\title{
Modeling of Balanced and Unbalanced Three-Phase Induction Motor under Balanced and Unbalanced Supply Based on Winding Function Method
}

\author{
Mohammad Jannati ${ }^{1}$, Tole Sutikno ${ }^{2}$, Nik Rumzi Nik Idris ${ }^{3}$, Mohd Junaidi Abdul Aziz ${ }^{4}$ \\ ${ }^{1,3,4}$ UTM-PROTON Future Drive Laboratory, Faculty of Electrical Engineering, Universiti Teknologi Malaysia \\ 81310 Skudai, Johor Bahru, Malaysia \\ ${ }^{2}$ Department of Electrical Engineering, Faculty of Industrial Technology, Universitas Ahmad Dahlan \\ UAD $3^{\text {rd }}$ Campus, Janturan 55164, Yogyakarta, Indonesia
}

\begin{tabular}{l} 
Article Info \\
\hline Article history: \\
Received Mar 8, 2015 \\
Revised May 12, 2015 \\
Accepted May 30, 2015 \\
\hline Keyword: \\
Balanced Induction Motor \\
Balanced Supply \\
Modeling \\
Unbalanced Induction Motor \\
Unbalanced Supply \\
Winding Function Method
\end{tabular}

\begin{abstract}
An accurate model of balanced and unbalanced three-phase Induction Motor (IM) under balanced and unbalanced supply conditions based on Winding Function Method (WFM) is presented in this work. In this paper, the unbalanced condition in three-phase IM is limited to stator winding openphase fault. The analysis of presented models is shown in details which allow predicting the performance of 3-phase IM under different conditions. Computer simulations were obtained using the MATLAB software for a three-phase squirrel cage IM. MATLAB simulation results show that the oscillation of the speed and electromagnetic torque has increased considerably due to the open-phase fault in stator windings.
\end{abstract}

Copyright (C) 2015 Institute of Advanced Engineering and Science. All rights reserved.

\section{Corresponding Authors:}

Mohammad Jannati and Nik Rumzi Nik Idris

UTM-PROTON Future Drive Laboratory, Faculty of Electrical Engineering,

Universiti Teknologi Malaysia

81310 Skudai, Johor Bahru, Malaysia

Email: jannatim94@yahoo.com,nikrumzi@fke.utm.my

\section{INTRODUCTION}

Three-phase Induction Motors (IMs) are commonly employed in many industrial applications due to their reliability, robustness, low cost, good performance and need little maintenance compared with other types of electrical machines [1].

The $\mathrm{d}-\mathrm{q}$ model is one of the most generally models for three-phase IMs which has been presented by Park. Detailed d-q modeling is used to represent healthy IMs and motors under fault conditions [2]-[5]. This model decreases the number of equations needed for simulation. However, it requires some modification in model structure for each fault condition in 3-phase IM [6]. Moreover the d-q model is based on the supposition that the stator windings are sinusoidal distributed. This assumption is caused the harmonics of the windings distribution are removed in the motor analysis. Detailed modeling of 3-phase IM under fault condition assists understanding motor dynamic behavior for choosing appropriate methods to detect faults and choosing suitable control strategies. A technique based on the real distribution of stator windings for modeling of three-phase IM has been proposed by Toliyat et al. [7], [8]. In this technique which is called Winding Function Method (WFM) has been used to study healthy electrical machines and many familiar faults in electrical machines such as cracked rotor end rings, broken rotor bars, short circuit and abnormal conditions of the stator windings [9]-[16]. 
When the 3-phase IM is connected directly to power supply or an inverter in the case of electrical drives, the operation of the machine cannot be done under operation of balanced power supply. From many researches, the unbalanced power supply has damaging result on the IM performance. It induces losses, vibration, heating and noise [17]-[22]. Consequently, unbalancing detection in the voltage applied is mandatory.

In this work, we present model of healthy and faulty three-phase IM (three-phase IM under stator winding open-circuit fault) under balanced and unbalanced power supply combined to the winding function theory. This paper is organized as follows: After introduction in section 1, in section 2, WFM model of healthy and faulty three-phase IM under balanced and unbalanced supply is discussed. The performance of the presented methods is analyzed and checked using Matlab software in section 3 and section 4 concludes the paper.

\section{WFM MODEL OF HEALTHY AND FAULTY THREE-PHASE IM UNDER BALANCED AND UNBALANCED SUPPLY}

The squirrel cage rotor of 3-phase IM and equivalent circuit of squirrel cage rotor in WFM is shown in Figure 1 and Figure 2 respectively.

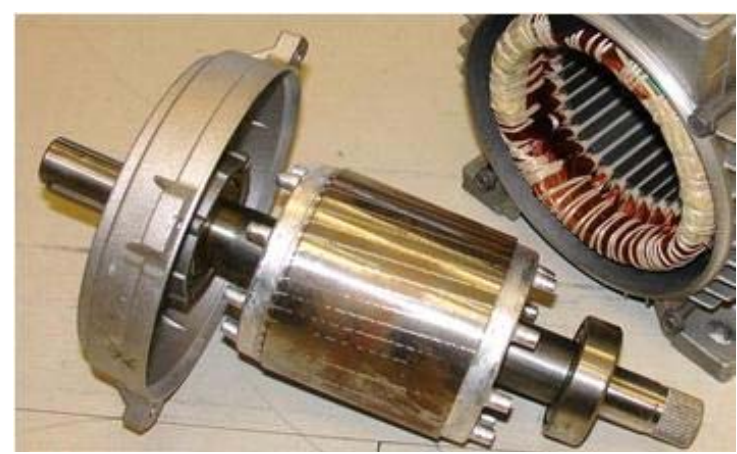

Figure 1. Squirrel cage rotor

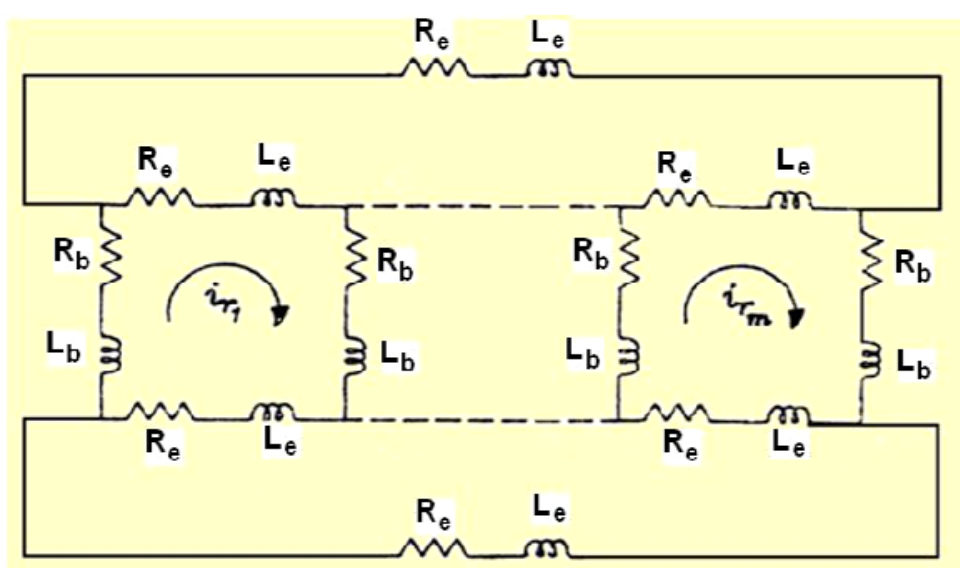

Figure 2. Equivalent circuit of squirrel cage rotor in WFM

Moreover, the equations of healthy 3-phase IM with "m" rotor bars can be written as equations (1) and (2) [7], [8]. 


$$
\begin{aligned}
& V_{s}=R_{s} I_{s}+\frac{d}{d t} \Lambda_{s} \\
& \Lambda_{s}=L_{s s} I_{s}+L_{s r} I_{r} \\
& V_{r}=R_{r} I_{r}+\frac{d}{d t} \Lambda_{r} \\
& \Lambda_{r}=L_{r r} I_{r}+L_{s r}^{T} I_{s} \\
& T_{e}=I_{s}^{T} \frac{\partial L_{s r}}{\partial \theta_{r m}} I_{r} \\
& \omega_{r m}=\frac{d \theta_{r m}}{d t}
\end{aligned}
$$

where:

$$
\begin{aligned}
& V_{s}=\left[\begin{array}{lll}
v_{a} & v_{b} & v_{c}
\end{array}\right]^{T}, I_{s}=\left[\begin{array}{lll}
i_{a} & i_{b} & i_{c}
\end{array}\right]^{T}, \Lambda_{s}=\left[\begin{array}{lll}
\Lambda_{a} & \Lambda_{b} & \Lambda_{c}
\end{array}\right]^{T}, I_{r}=\left[\begin{array}{llll}
i_{r 1} & i_{r 2} & \ldots & i_{r m}
\end{array}\right]^{T} \\
& \Lambda_{r}=\left[\begin{array}{llll}
\Lambda_{r 1} & \Lambda_{r 2} & \ldots & \Lambda_{r m}
\end{array}\right]^{T}, V_{r}=\left[\begin{array}{llll}
v_{r 1} & v_{r 2} & \ldots & v_{r m}
\end{array}\right]^{T}=\left[\begin{array}{llll}
0 & 0 & \ldots & 0
\end{array}\right]^{T} \\
& R_{s}=\left[\begin{array}{ccc}
r_{s} & 0 & 0 \\
0 & r_{s} & 0 \\
0 & 0 & r_{s}
\end{array}\right], L_{s s}=\left[\begin{array}{lll}
L_{a a} & L_{a b} & L_{a c} \\
L_{b a} & L_{b b} & L_{b c} \\
L_{c a} & L_{c b} & L_{c c}
\end{array}\right], L_{s r}=\left[\begin{array}{llll}
L_{a r 1} & L_{a r 2} & \ldots & L_{a r m} \\
L_{b r 1} & L_{b r 2} & \ldots & L_{b r m} \\
L_{c r 1} & L_{c r 2} & \ldots & L_{c r m}
\end{array}\right] \\
& R_{r}=\left[\begin{array}{cccccc}
2\left(R_{b}+R_{e}\right) & -R_{b} & 0 & \ldots & 0 & -R_{b} \\
-R_{b} & 2\left(R_{b}+R_{e}\right) & -R_{b} & \ldots & 0 & 0 \\
\ldots & \ldots & \ldots & \ldots & \ldots & \ldots \\
0 & 0 & 0 & \ldots & 2\left(R_{b}+R_{e}\right) & -R_{b} \\
-R_{b} & 0 & 0 & \ldots & -R_{b} & 2\left(R_{b}+R_{e}\right)
\end{array}\right] \\
& L_{r r}=\left[\begin{array}{ccccc}
L_{m r}+2\left(L_{b}+L_{e}\right) & L_{r_{1} r_{2}}-L_{b} & L_{r_{1} r_{3}} & \ldots & L_{r_{1} r_{m}}-L_{b} \\
L_{r_{2} r_{1}}-L_{b} & L_{m r}+2\left(L_{b}+L_{e}\right) & L_{r_{2} r_{3}}-L_{b} & \ldots & L_{r_{2} r_{m}} \\
L_{r_{3} r_{1}} & L_{r_{3} r_{2}}-L_{b} & L_{m r}+2\left(L_{b}+L_{e}\right) & \ldots & L_{r_{3} r_{m}} \\
\ldots & \ldots & \ldots & \ldots & \ldots \\
L_{r_{m} r_{1}}-L_{b} & L_{r_{m} r_{2}} & L_{r_{m} r_{3}} & \ldots & L_{m r}+2\left(L_{b}+L_{e}\right)
\end{array}\right]
\end{aligned}
$$

In (2), $\left[R_{s}\right]$ is $3 \times 3$ consists of resistance of each coil, $\left[R_{r}\right]$ is $m \times m$ matrix where, $R_{e}$ is the end ring segment resistance and $R_{b}$ is the rotor bar resistance. The matrix $\left[\mathrm{L}_{\mathrm{ss}}\right]$ is $3 \times 3$ matrix. The mutual inductance matrix $\left[\mathrm{L}_{\mathrm{sr}}\right]$ is $3 \times \mathrm{m}$ matrix included of the mutual inductances between the stator coils and the rotor bars. $\mathrm{L}_{\mathrm{mr}}$ is the magnetizing inductance of each rotor bar. $\mathrm{L}_{b}$ and $\mathrm{L}_{e}$ are rotor bar leakage inductance and rotor end ring leakage inductance. Moreover, $\mathrm{L}_{\text {rirj }}$ is the mutual inductance between two rotor bars.

The motor that is studied in this paper has 28 rotor bars and 36 stator slots. Figure 3 and Figure 4 show the turn function of the stator phases and the turn function of first rotor bar for the healthy machine respectively (for the turn function of second rotor bar, the waveform of Figure 4 is shifted to the right by $2 \pi / 28=\pi / 14)$.

In WFM, winding function is defined as following equation [7], [8]:

$$
N(\varphi)=n(\varphi)-\langle n(\varphi)\rangle
$$

where, $\mathrm{n}(\varphi)$ is the turn function and $\langle\mathrm{n}(\varphi)>$ is the average value of turn function. Based on equation (3), Figure 3 and Figure 4, the winding function of the stator phases and the winding function of first rotor bar are shown in Figure 5 and Figure 6 respectively. 


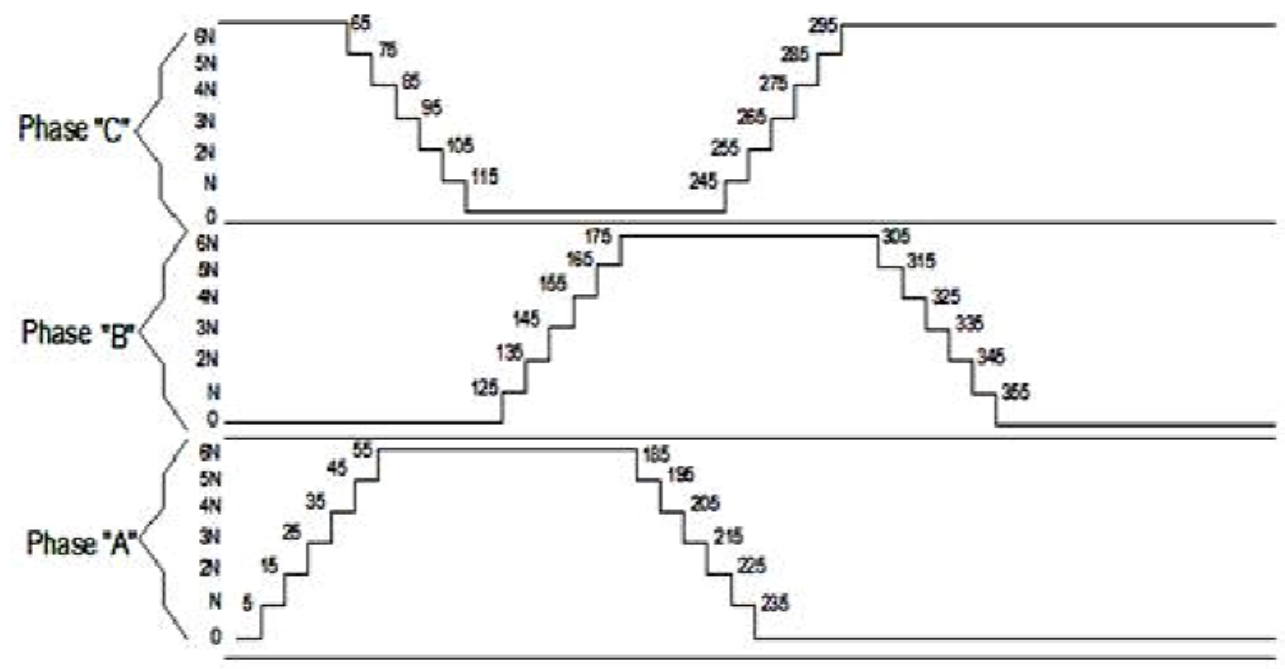

Figure 3. Turn function of stator phases

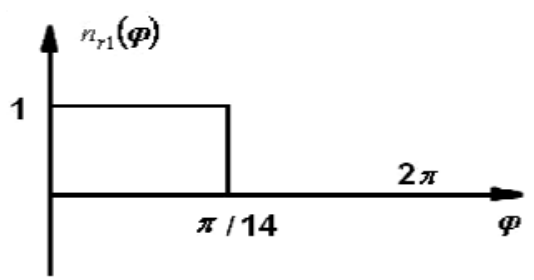

Figure 4. Turn function of first rotor bar

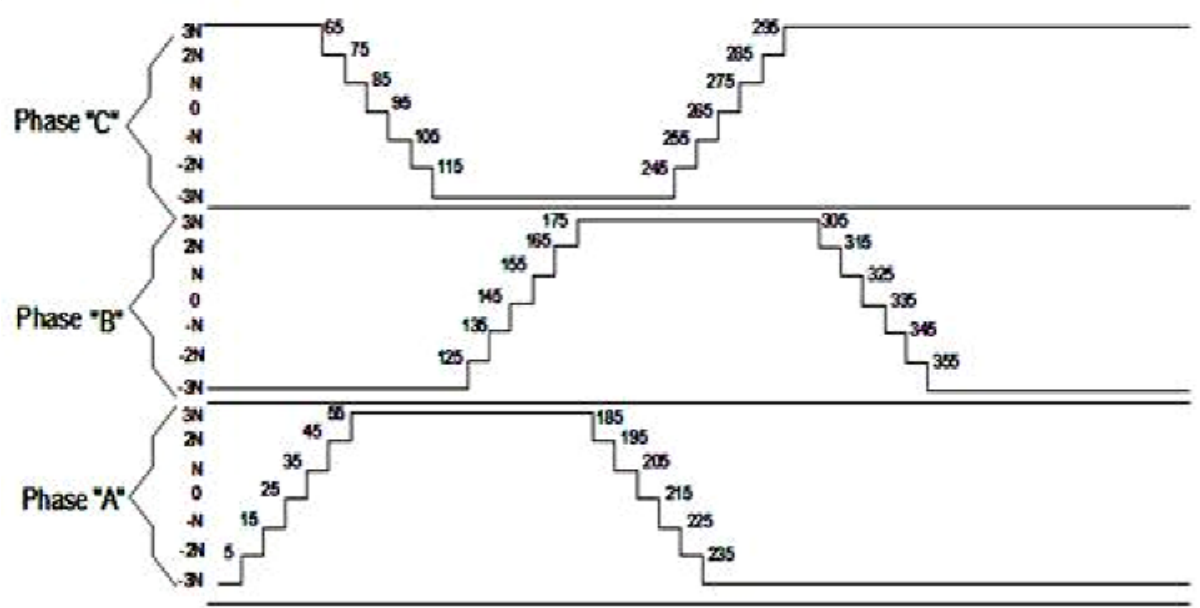

Figure 5. Winding function of stator phases

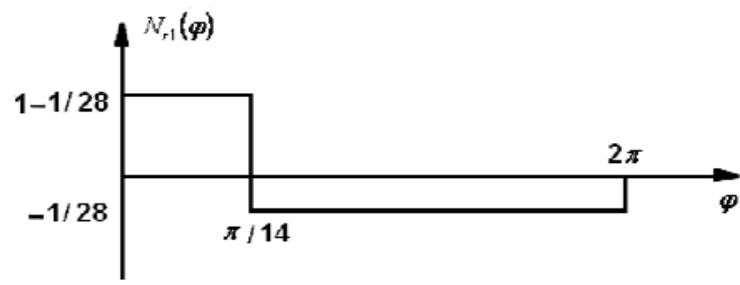

Figure 6. Winding function of first rotor bar 
The mutual inductance between windings $B$ and $A\left(L_{B A}\right)$ in terms of turn function and winding function is calculated by [7]:

$$
L_{B A}=\frac{\mu_{o} r l}{g} \int_{0}^{2 \pi} N_{A}(\varphi) n_{B}(\varphi) d \varphi
$$

where " $\mathrm{r}$ " is rotor radius, "l" is stack length, " $\mathrm{g}$ " is effective air gap, $\mathrm{n}_{\mathrm{B}}(\varphi)$ is turn function of winding B and $\mathrm{N}_{\mathrm{A}}(\varphi)$ is winding function of winding A. Moreover, $\mu_{\mathrm{o}}=4 \pi \mathrm{E}-7$. From Figures 3-6 and equation (4), $\mathrm{L}_{\mathrm{ss}}, \mathrm{L}_{\mathrm{sr}}$ and $\mathrm{L}_{\mathrm{rr}}$ can be calculated as:

$$
\begin{aligned}
& L_{a a}: \\
& L_{a a}=\frac{\mu_{o} r l}{g}\left[\int_{5}^{15}(N)(-2 N) d \varphi+\int_{15}^{25}(2 N)(-N) d \varphi+\int_{35}^{45}(4 N)(N) d \varphi\right. \\
& +\int_{45}^{55}(5 N)(2 N) d \varphi+\int_{55}^{185}(6 N)(3 N) d \varphi+\int_{185}^{195}(5 N)(2 N) d \varphi \\
& \left.+\int_{195}^{205}(4 N)(N) d \varphi+\int_{215}^{225}(2 N)(-N) d \varphi+\int_{225}^{235}(N)(-2 N) d \varphi\right] \\
& =\frac{\mu_{o} r l}{g} \pi N^{2}\left(\frac{127}{9}\right) \\
& L_{a b} \text { : } \\
& L_{a b}=\frac{\mu_{o} r l}{g}\left[\int_{5}^{15}(N)(-3 N) d \varphi+\int_{15}^{25}(2 N)(-3 N) d \varphi\right. \\
& +\int_{25}^{35}(3 N)(-3 N) d \varphi+\int_{35}^{45}(4 N)(-3 N) d \varphi+\int_{45}^{55}(5 N)(-3 N) d \varphi \\
& +\int_{55}^{125}(6 N)(-3 N) d \varphi+\int_{125}^{135}(6 N)(-2 N) d \varphi+\int_{135}^{145}(6 N)(-N) d \varphi \\
& +\int_{155}^{165}(6 N)(N) d \varphi+\int_{165}^{175}(6 N)(2 N) d \varphi+\int_{175}^{185}(6 N)(3 N) d \varphi \\
& +\int_{185}^{195}(5 N)(3 N) d \varphi+\int_{195}^{205}(4 N)(3 N) d \varphi+\int_{205}^{215}(3 N)(3 N) d \varphi \\
& \left.+\int_{215}^{225}(2 N)(3 N) d \varphi+\int_{225}^{235}(N)(3 N) d \varphi\right]=-\frac{\mu_{o} r l}{g} \pi N^{2}(6) \\
& L_{a c}: \\
& L_{a c}=\frac{\mu_{o} r l}{g}\left[\int_{5}^{15}(N)(3 N) d \varphi+\int_{15}^{25}(2 N)(3 N) d \varphi\right. \\
& +\int_{25}^{35}(3 N)(3 N) d \varphi+\int_{35}^{45}(4 N)(3 N) d \varphi+\int_{45}^{55}(5 N)(3 N) d \varphi \\
& +\int_{55}^{65}(6 N)(3 N) d \varphi+\int_{65}^{75}(6 N)(2 N) d \varphi+\int_{75}^{85}(6 N)(N) d \varphi \\
& +\int_{95}^{105}(6 N)(-N) d \varphi+\int_{105}^{115}(6 N)(-2 N) d \varphi+\int_{115}^{185}(6 N)(-3 N) d \varphi \\
& +\int_{185}^{195}(5 N)(-3 N) d \varphi+\int_{195}^{205}(4 N)(-3 N) d \varphi+\int_{205}^{215}(3 N)(-3 N) d \varphi \\
& \left.+\int_{215}^{225}(2 N)(-3 N) d \varphi+\int_{225}^{235}(N)(-3 N) d \varphi\right]=-\frac{\mu_{o} r l}{g} \pi N^{2}(6)
\end{aligned}
$$


Therefore $\mathrm{L}_{\mathrm{ss}}$ is obtained as equation (8).

$$
\begin{aligned}
& L_{s s}=\frac{\mu_{o} r l}{g} \pi N^{2}\left[\begin{array}{ccc}
\frac{127}{9} & -6 & -6 \\
-6 & \frac{127}{9} & -6 \\
-6 & -6 & \frac{127}{9}
\end{array}\right] \\
& \boldsymbol{L}_{s r}: \\
& L_{s r}=\frac{\mu_{o} r l}{g} \int_{0}^{2 \pi} N_{s}(\varphi) n_{r}(\varphi) d \varphi
\end{aligned}
$$

which gives,

$$
\begin{aligned}
& 0 \leq \theta_{r m}\langle\pi-\alpha: \\
& L_{s r}=\frac{\mu_{o} r l}{g}\left[\int_{\theta_{r m}}^{\theta_{r m}+\alpha} 1 \times \frac{N}{2} d \varphi\right]=\left(\frac{\mu_{o} r l}{g}\right)\left(\frac{N}{2}\right) \alpha \\
& \pi-\alpha \leq \theta_{r m}\langle\pi: \\
& L_{s r}=\frac{\mu_{o} r l}{g}\left[\int_{\theta_{r m}}^{\pi} \frac{N}{2} d \varphi+\int_{\pi}^{\theta_{r m}+\alpha}-\frac{N}{2} d \varphi\right]=\left(\frac{\mu_{o} r l}{g}\right)\left(\frac{N}{2}\right)\left(2 \pi-2 \theta_{r m}-\alpha\right) \\
& \pi \leq \theta_{r m}\langle 2 \pi-\alpha: \\
& L_{s r}=\frac{\mu_{o} r l}{g}\left[\int_{\theta_{r m}}^{\theta_{r m}+\alpha}-\frac{N}{2} d \varphi\right]=-\left(\frac{\mu_{o} r l}{g}\right)\left(\frac{N}{2}\right) \alpha \\
& 2 \pi-\alpha \leq \theta_{r m}\langle 2 \pi: \\
& L_{s r}=\frac{\mu_{0} r l}{g}\left[\int_{\theta_{r m}}^{2 \pi}-\frac{N}{2} d \varphi+\int_{2 \pi}^{\theta_{r m}+\alpha} \frac{N}{2} d \varphi\right]=-\left(\frac{\mu_{o} r l}{g}\right)\left(\frac{N}{2}\right)\left(4 \pi-2 \theta_{r m}-\alpha\right)
\end{aligned}
$$

Therefore $\mathrm{L}_{\mathrm{sr}}$ is obtained as equation (13).

$$
L_{s r}=\frac{\mu_{o} r l N}{g}\left\{\begin{array}{lc}
\frac{\alpha}{2} & 0 \leq \theta_{r m}<\pi-\alpha \\
-\theta_{r m}+\pi-\frac{\alpha}{2} & \pi-\alpha \leq \theta_{r m}<\pi \\
-\frac{\alpha}{2} & 2 \pi-\alpha \leq \theta_{r m}<2 \pi-\alpha \\
-\theta_{r m}-2 \pi+\frac{\alpha}{2} &
\end{array}\right.
$$

As mentioned before, the motor that is studied in this paper has 28 rotor bars $(\alpha=2 \pi / 28=\pi / 14)$ and 36 stator slots. Therefore equation (13) can be written as equation (14).

$$
L_{a_{1} r_{1}}=\frac{\mu_{o} r l N}{g}\left\{\begin{array}{lc}
\frac{\pi}{28} & 0 \leq \theta_{r m}<\frac{13 \pi}{14} \\
\frac{27 \pi}{28}-\theta_{r m} & \frac{13 \pi}{14} \leq \theta_{r m}<\pi \\
-\frac{\pi}{28} & \pi \leq \theta_{r m}<\frac{27 \pi}{14} \\
-\frac{55 \pi}{28}+\theta_{r m} & \frac{27 \pi}{14} \leq \theta_{r m}<2 \pi
\end{array}\right.
$$


Therefore $\mathrm{L}_{\mathrm{ar} 1}$ (inductance between the phase "a" of the stator winding and first rotor bar) is obtained as follows:

$$
L_{a r_{1}}=L_{a_{1} r_{2}}+L_{a_{2} r_{1}}+L_{a_{3} r_{1}}+L_{a_{4} r_{1}}+L_{a_{5} r_{1}}+L_{a_{6} r_{1}}
$$

which gives,

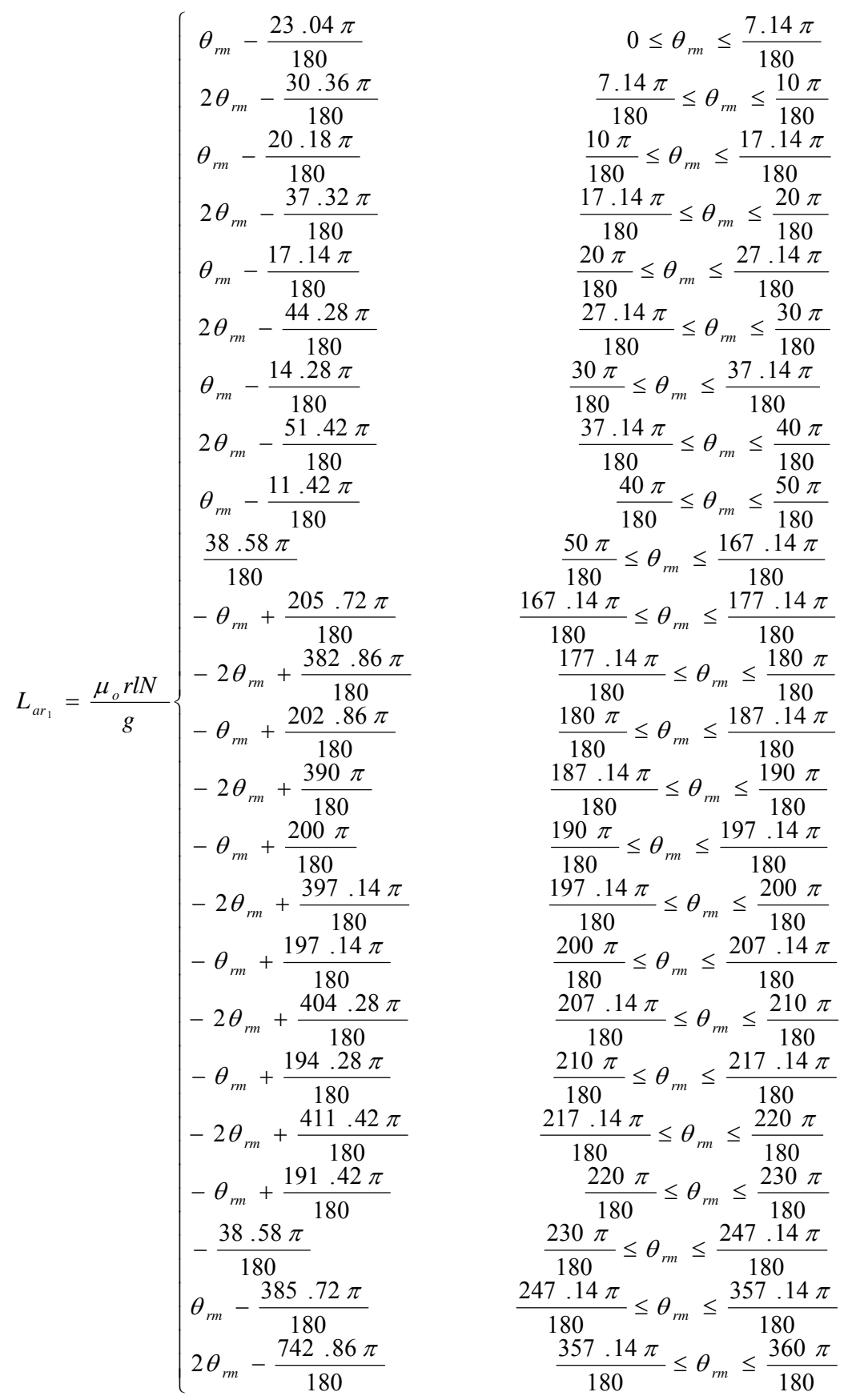

The same process can be done for " $\mathrm{L}_{\mathrm{ar} 2}, \mathrm{~L}_{\mathrm{ar} 3}, \ldots, \mathrm{L}_{\mathrm{br} 1}, \mathrm{~L}_{\mathrm{br} 2}, \ldots$ and $\mathrm{L}_{\mathrm{cr} 1}, \mathrm{~L}_{\mathrm{cr} 2}, \ldots$ ”.

$L_{r r}:$

$L_{r_{1} r_{1}}=\frac{\mu_{o} r l}{g} \int_{0}^{2 \pi} N_{r_{1}}(\varphi) n_{r_{1}}(\varphi) d \varphi=-\frac{\mu_{o} r l}{g} \times \frac{\alpha^{2}}{2 \pi}$ 
As the rotor bars are the same, therefore the general form of rotor inductances are obtained as following equation:

$$
L_{r_{i} r_{j}}=-\frac{\mu_{o} r l}{g} \times \frac{\pi}{392}
$$

Equations (1) and (2) can be written as (19) and (20).

$$
\begin{aligned}
& {\left[\begin{array}{c}
v_{a}-v_{b} \\
v_{b}-v_{c}
\end{array}\right]=\left[\begin{array}{ccc}
r_{s} & -r_{s} & 0 \\
0 & r_{s} & -r_{s}
\end{array}\right]\left[\begin{array}{l}
i_{a} \\
i_{b} \\
i_{c}
\end{array}\right]+\frac{d}{d t}\left[\begin{array}{l}
\Lambda_{a}-\Lambda_{b} \\
\Lambda_{b}-\Lambda_{c}
\end{array}\right]} \\
& {\left[\begin{array}{c}
\Lambda_{a}-\Lambda_{b} \\
\Lambda_{b}-\Lambda_{c} \\
0
\end{array}\right]=\left[\begin{array}{ccc}
L_{a a}-L_{b a} & L_{a b}-L_{b b} & L_{a c}-L_{b c} \\
L_{b a}-L_{c a} & L_{b b}-L_{c b} & L_{b c}-L_{c c} \\
1 & 1 & 1
\end{array}\right]\left[\begin{array}{c}
i_{a} \\
i_{b} \\
i_{c}
\end{array}\right]} \\
& +\left[\begin{array}{cccc}
L_{a r 1}-L_{b r 1} & L_{a r 2}-L_{b r 2} & \ldots & L_{a r 28}-L_{b r 28} \\
L_{b r 1}-L_{c r 1} & L_{b r 2}-L_{c r 2} & \ldots & L_{b r 28}-L_{c r 28} \\
0 & 0 & \ldots & 0
\end{array}\right]\left[\begin{array}{c}
i_{r 1} \\
i_{r 2} \\
\vdots \\
i_{r 28}
\end{array}\right]
\end{aligned}
$$

Equations of 3-phase IM when one of the stator phases opened have the similar structure to the healthy 3-phase machine equations. The only different is that, in the faulty mode, the row and column for the faulted phase is removed. Therefore, during stator winding open-phase fault, (19) and (20) change to (21) and (22) (in this paper it is assumed that a phase cut-off fault is occurred in phase "c" of the stator windings).

$$
\begin{aligned}
& {\left[\begin{array}{c}
v_{a}-v_{b} \\
v_{b}-v_{c}
\end{array}\right]=\left[\begin{array}{cc}
r_{s} & -r_{s} \\
0 & r_{s}
\end{array}\right]\left[\begin{array}{l}
i_{a} \\
i_{b}
\end{array}\right]+\frac{d}{d t}\left[\begin{array}{c}
\Lambda_{a}-\Lambda_{b} \\
\Lambda_{b}-\Lambda_{c}
\end{array}\right]} \\
& {\left[\begin{array}{c}
\Lambda_{a}-\Lambda_{b} \\
\Lambda_{b}-\Lambda_{c}
\end{array}\right]=\left[\begin{array}{ll}
L_{a a}-L_{b a} & L_{a b}-L_{b b} \\
L_{b a}-L_{c a} & L_{b b}-L_{c b}
\end{array}\right]\left[\begin{array}{c}
i_{a} \\
i_{b}
\end{array}\right]} \\
& +\left[\begin{array}{llll}
L_{a r 1}-L_{b r 1} & L_{a r 2}-L_{b r 2} & \ldots & L_{a r 28}-L_{b r 28} \\
L_{b r 1}-L_{c r 1} & L_{b r 2}-L_{c r 2} & \ldots & L_{b r 28}-L_{c r 28}
\end{array}\right]\left[\begin{array}{c}
i_{r 1} \\
i_{r 2} \\
\vdots \\
i_{r 28}
\end{array}\right]
\end{aligned}
$$

\section{SIMULATION RESULTS}

The WF model presented in the section 2 has been implemented in the Matlab (M-File) environment. The 3-phase IM used in this paper is $7.5 \mathrm{Hp}, 400 \mathrm{~V}, 60 \mathrm{~Hz}, 2$ Poles. Their detailed motor parameters are given as follows:

Effective air gap: $\mathrm{g}=0.9874 \mathrm{E}-3 \mathrm{~m}$

Stack length: $1=102.4128 \mathrm{E}-3 \mathrm{~m}$

Rotor radius: $\mathrm{r}=63.2968 \mathrm{E}-3 \mathrm{~m}$

Stator resistance: $r_{s}=1.76 \Omega$

Rotor bar resistance: $R_{b}=68.34 \mathrm{E}-6 \Omega$

Rotor end ring segment resistance: $\mathrm{R}_{\mathrm{e}}=1.56 \mathrm{E}-6 \Omega$

Rotor bar leakage inductance: $\mathrm{L}_{\mathrm{b}}=0.28 \mathrm{E}-6 \mathrm{H}$

Rotor end ring leakage inductance: $\mathrm{L}_{\mathrm{e}}=0.03 \mathrm{E}-6 \mathrm{H}$

Inertia: $\mathrm{J}=0.03 \mathrm{~kg} . \mathrm{m}^{2}$ 
The 3-phase motor studied under two different source conditions: A: sinusoidal 3-phase power supply (Figure 7(a) and Figure 8(a)) and B: unbalanced non-sinusoidal 3-phase power supply (Figure 7(b) and Figure 8(b)). Figure 7(a) and Figure 7(b) show the simulation results of the 3-phase IM under healthy condition and Figure 8(a) and Figure 8(b) show the simulation results of the 3-phase IM under open-phase fault. In Figure 7 and Figure 8 a step load torque equal to 5N.m at third second is applied. Moreover, in Figure 8 a phase cut-off fault is happened at starting and in phase "c". The supply voltage values used in Figure 7(a), Figure 7(b), Figure 8(a) and Figure 8(b) are:

Figure 7(a):

$\mathrm{V}_{\mathrm{a}}=400 * \cos (120 * \mathrm{pi} * \mathrm{t})$

$\mathrm{V}_{\mathrm{b}}=400 * \cos (120 * \mathrm{pi} * \mathrm{t}-2 * \mathrm{pi} / 3)$

$\mathrm{V}_{\mathrm{c}}=400 * \cos (120 * \mathrm{pi} * \mathrm{t}+2 * \mathrm{pi} / 3)$

Figure 7(b):

$\mathrm{V}_{\mathrm{a}}=400 * \cos (120 * \mathrm{pi} * \mathrm{t})$

$\mathrm{V}_{\mathrm{b}}=350 * \cos (120 * \mathrm{pi} * \mathrm{t}-2 * \mathrm{pi} / 3)+20 * \cos (3 *(120 * \mathrm{pi} * \mathrm{t}-2 * \mathrm{pi} / 3))$

$\mathrm{V}_{\mathrm{c}}=300 * \cos (120 * \mathrm{pi} * \mathrm{t}+2 * \mathrm{pi} / 3)+30 * \cos (5 *(120 * \mathrm{pi} * \mathrm{t}+2 * \mathrm{pi} / 3))$

Figure 8(a):

$\mathrm{V}_{\mathrm{a}}=400 * \cos \left(120 * \mathrm{pi}^{*} \mathrm{t}\right)$

$\mathrm{V}_{\mathrm{b}}=400 * \cos (120 * \mathrm{pi} * \mathrm{t}-2 * \mathrm{pi} / 3)$

Figure 8(b):

$\mathrm{V}_{\mathrm{a}}=400 * \cos (120 * \mathrm{pi} * \mathrm{t})$

$\mathrm{V}_{\mathrm{b}}=300 * \cos (120 * \mathrm{pi} * \mathrm{t}-2 * \mathrm{pi} / 3)+20 * \cos (4 *(120 * \mathrm{pi} * \mathrm{t}-2 * \mathrm{pi} / 3))$

Figure 7 and Figure 8 illustrate the waveform of stator a-axis current, first rotor bar current, electromagnetic torque and machine speed. It is observed from the stator and rotor current waveforms that machine currents are balanced and sinusoidal but with different amplitudes in healthy, faulty and balanced and unbalance sinusoidal and non-sinusoidal source conditions. Based on simulation results of Figure 8 , it is concluded that, the oscillations of the speed and electromagnetic torque has increased considerably due to the open-phase fault in stator windings. Moreover, based on this Figure, the stator and rotor currents have increased at open-phase condition compared with normal condition. Moreover, in Figure 7(a) the motor speed reach to steady-state after $\sim 0.2 \mathrm{~s}$, in Figure 7 (b) the motor speed reach to steady-state after $\sim 0.3 \mathrm{~s}$ in Figure 8 (a) the motor speed reach to steady-state after $\sim 1.2 \mathrm{~s}$ in Figure $8(\mathrm{~b})$ the motor speed reach to steadystate after $\sim 1.4 \mathrm{~s}$ 

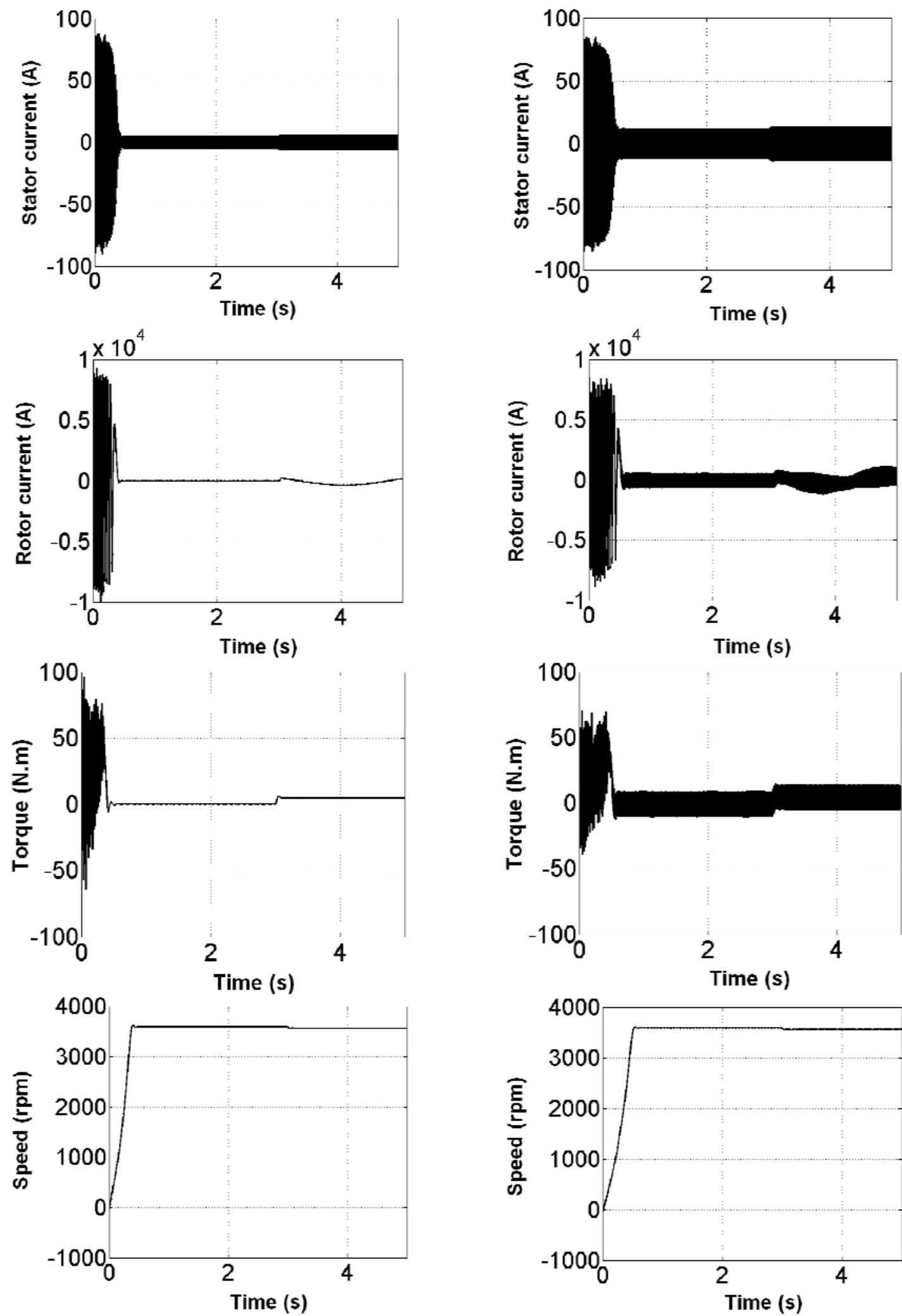

(a)

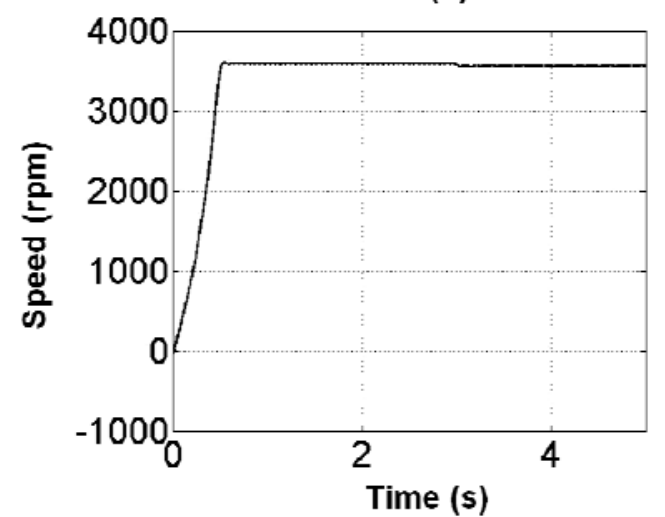

(b)

Figure 7. Simulation results of healthy 3-phase IM; (a): balanced supply, (b): unbalanced supply 

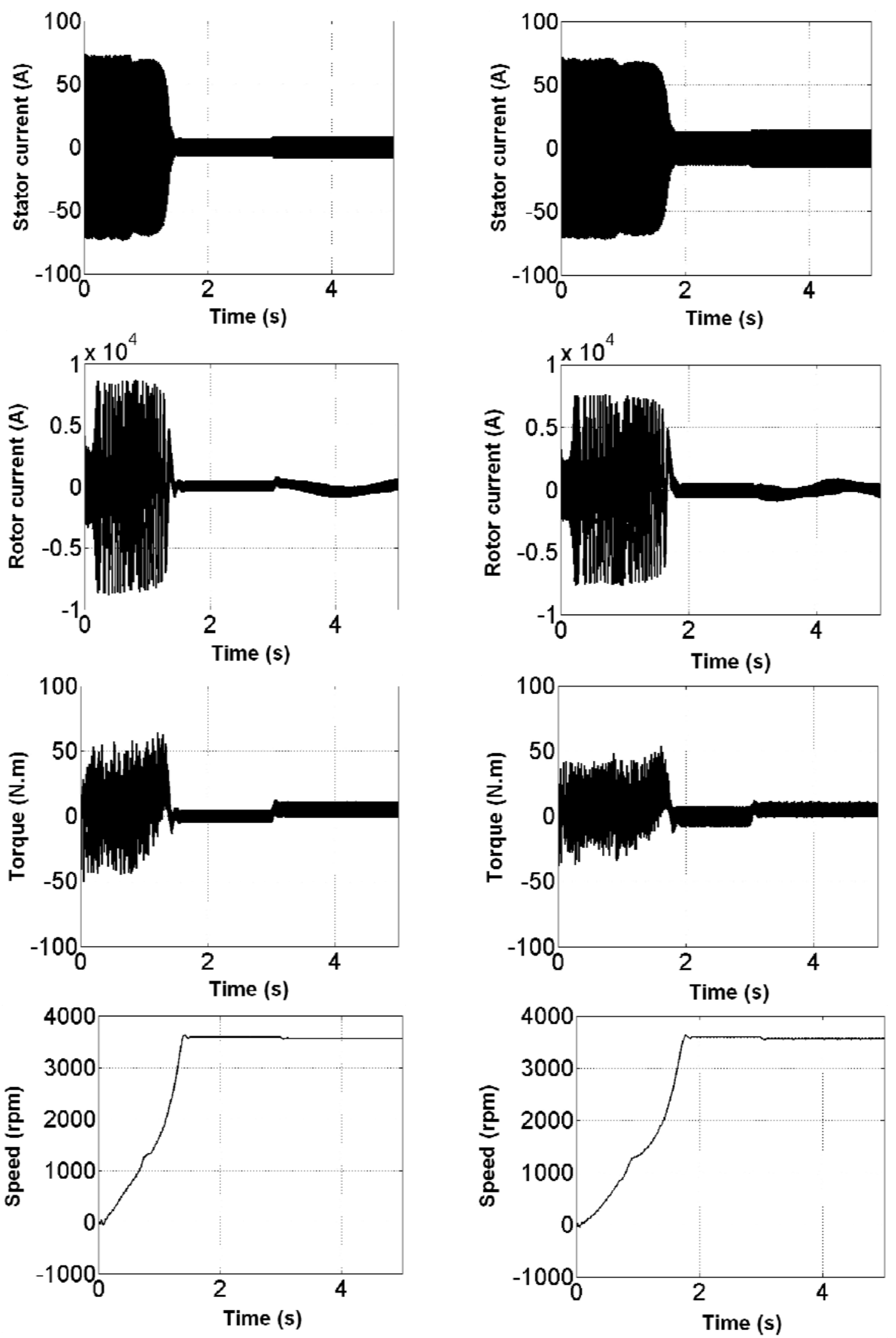

(a)

(b)

Figure 8. Simulation results of faulty 3-phase IM; (a): balanced supply, (b): unbalanced supply 


\section{CONCLUSION}

The research on fault detection and fault tolerant control of 3-phase IM often requires an accurate model. For this purpose, in this paper we have to elaborate an exact model which allows us to predict the performance of 3-phase IM under different conditions. The presented methods to model of 3-phas IM in this paper is based on winding function theory. This work has investigated the different operating conditions in squirrel cage 3-phase IM namely healthy and stator winding open-phase fault conditions under balanced and unbalanced power supply. Finally, Matlab simulation results are presented to show the dynamic behavior of 3-phase IM under these conditions.

\section{REFERENCES}

[1] A.E. Fitzgerald, et.al., "Electric Machinery", McGraw-Hill, 2003.

[2] M. Jannati, et.al., "Speed Sensorless Vector Control of Unbalanced Three-Phase Induction Motor with Adaptive Sliding Mode Control”, International Journal of Power Electronics and Drive Systems (IJPEDS), vol. 4, pp. 406418, 2014.

[3] S.H. Asgari, et.al., "Modeling of three-phase induction motor with two stator phases open-circuit", In 2014 IEEE Conference on Energy Conversion (CENCON), pp. 231-236, 2014.

[4] P.C. Krause, "Analysis of Electric Machinery", McGraw-Hill, 1986.

[5] M. Jannati, et.al., "Modeling and RFOC of faulty three-phase IM using Extended Kalman Filter for rotor speed estimation", In 8th International Power Engineering and Optimization Conference (PEOCO), pp. 270-275, 2014.

[6] M. Jannati, et.al., 'Modeling and speed estimation of a faulty 3-phase induction motor by using extended Kalman filter”, In 2014 IEEE Symposium on Computer Applications and Industrial Electronics (ISCAIE), pp. 76-81, 2014.

[7] H.A. Toliyat, et.al., "Analysis of a concentrated winding induction machine for Adjustable Speed Drive Applications-part I (Motor Analysis)", IEEE Transaction on Energy Conversion, vol. 6, pp. 679-684, 1991.

[8] H.A. Toliyat, et.al., "Analysis of a concentrated winding induction machine for adjustable speed drive applicationspart II (Motor design and performance analysis)", IEEE Transaction on Energy Conversion, vol. 6, pp. 685-692, 1991.

[9] H.A. Toliyat and T.A. Lipo, "Transient analysis of cage induction machines under stator, rotor bar and end ring faults", IEEE Transaction on Energy Conversion, vol. 10, pp. 241-247, 1995.

[10] J. Milimonfared, et.al., "A novel approach for broken rotor bar detection in cage induction motors", IEEE Transaction on Industrial Applications, vol. 35, pp. 1000-1006, 1999.

[11] J. Faiz, B.M. Ebrahimi, M. Valavi, and T.A. Toliyat, "Mixed eccentricity fault diagnosis in salient-pole synchronous generator using modified winding function method", Progress In Electromagnetics Research B, vol. 11, pp. 155-172, 2009.

[12] S. Nandi and T.A. Toliyat, "Novel frequency-domain-based technique to detect stator interturn faults in induction machines using stator-induced voltages after switch-off", IEEE Transaction on Industrial Applications, vol. 38, pp. 101-109, 2002.

[13] M.G. Joksimovic and J. Penman, "The detection of inter-turn short circuits in the stator windings of operating motors", IEEE Transaction on Industrial Electronics, vol. 47, pp. 1078-1084, 2000.

[14] J. Faiz, et.al., "Locating broken bars in line-start and inverter-fed induction motors using modified winding function method", Electromagnetics, vol. 32, pp. 173-192, 2012.

[15] T. Kim, et.al., "The internal fault analysis of brushless DC motors based on the winding function theory", IEEE Transactions on Magnetics, vol. 45, pp. 2090-2096, 2009.

[16] J. Faiz and M. Ojaghi, "Unified winding function approach for dynamic simulation of different kinds of eccentricity faults in cage induction machines", IET electric power applications, vol. 3, pp. 461-470, 2009.

[17] D. Mirabbasi, et.al., "Effect of unbalanced voltage on operation of induction motors and its detection", In International Conference on Electrical and Electronics Engineering (ELECO 2009), pp. 189-192, 2009.

[18] D. Kouchih, et.al., "Diagnosis of cage induction motors subject to unbalanced supply voltage conditions including space and time harmonics", In 14th International Conference on Sciences and Techniques of Automatic Control and Computer Engineering (STA), pp. 486-492, 2013.

[19] S.M. Ahmed, et.al., "Diagnosis of Stator Turn-to-Turn Fault and Stator Voltage Unbalance Fault Using ANFIS", International Journal of Electrical and Computer Engineering (IJECE), vol. 3, pp. 129-135, 2013.

[20] Y.J. Wang, "An analytical study on steady-state performance of an induction motor connected to unbalanced threephase voltage", In Power Engineering Society Winter Meeting, pp. 159-164, 2000.

[21] S. Das, et.al., "Separating induction Motor Current Signature for stator winding faults from that due to supply voltage unbalances", In 1st International Conference on Power and Energy in NERIST (ICPEN), pp. 1-6, 2012.

[22] C.T. Raj, et.al., "Performance Analysis of a Three-Phase Squirrel-Cage Induction Motor under Unbalanced Sinusoidal and Balanced Non-Sinusoidal Supply Voltages", In International Conference on Power Electronics, Drives and Energy Systems (PEDES'06), pp. 1-4, 2006. 